\section{Letramento e argumentação no ensino de língua portuguesa}

Literacy and argumentation in
Portuguese Language Teaching

Isabel Cristina Michelan de AZEVEDO (UFS) icmazevedo@hotmail.com

Glícia Marili Azevedo de Medeiros TINOCO (UFRN) glicia_azevedo@yahoo.com.br

Recebido em: 15 de out. de 2018. Aceito em: 20 de fev. de 2019.
AZEVEDO, Isabel Cristina Michelan de; TINOCO, Glícia Marili Azevedo de Medeiros. Letramento e argumentação no ensino de língua portuguesa.

Entrepalavras, Fortaleza, v. 9, n. 1, p. 18-35, jan-abr/2019.

Resumo: A ressignificação do ensino de língua portuguesa vem sendo realizada por diferentes projetos de intervenção desenvolvidos, sobretudo, por professores vinculados ao Mestrado Profissional em Letras, dentre os quais, alguns já estão engajados em novos projetos em fase doutoral. Desse grande esforço em rede nacional, discutimos, neste artigo, como os estudos de letramento (KLEIMAN, 1995; 2000; STREET 2014 [1995]) e de argumentação (PERELMAN; OLBRECHTS-TYTECA, 1996 [1958]) podem se configurar como aportes para repensarmos o ensino da argumentação. Assim, pretendemos colaborar com as reflexões sobre os estudos da argumentação aplicados ao ensino de línguas, tendo em vista a necessidade de formação de professores em nível de graduação e de pós-graduação. Por concebermos a argumentação como um processo interacional (PLANTIN, 2010 [1996]), discursivo, complexo e multidimensional, objetivamos discutir as características de práticas pedagógicas que pretendem promover pontes entre os usos sociais da escrita e a argumentação, exigência para a formação cidadã. Para tanto, empreendemos um estudo exploratório, de natureza qualitativa 
e interpretativista, por isso tomamos por referência as pesquisas de Ribeiro (2015) e Aquino (2018) que submeteram o uso da leitura e escrita às necessidades sociais dos estudantes de ensino fundamental. Os resultados apontam que o trabalho com a argumentação pode ser um meio privilegiado para formar sujeitos com posicionamentos políticos que demonstrem raciocínio lógico, plausível e ético dentro e fora da escola.

Palavras-chave: Letramento. Argumentação. Ensino de língua portuguesa.

Abstract: The resignification of portuguese language teaching has been realized through different interventional projects developed, mostly, by teachers linked to the Professional Master's Degree in Languages (PROFLETRAS), some of which are already engaged in new projects in doctoral phase. From this great nationwide effort, we discuss, in this paper, how literacy studies (KLEIMAN, 1995; 2000; STREET 2014 [1995]) and argumentation (PERELMAN; OLBRECHTS-TYTECA, 1996 [1958]) may be seen as bases from which we may rethink the teaching of argumentation. Therefore, we intend to contribute with reflections on the studies of argumentation to the teaching of languages, having in mind the necessity to capacitate new teachers in both graduation and post-graduation levels. For conceiving argumentation as an interactional, discursive, complex and multidimensional process (PLANTIN, 2010 [1996]), this paper aims to discuss the characteristics of pedagogical practices that intend to promote links between the social uses of writing and argumentation, requirements for a citizen formation. For that purpose, we have developed an exploratory study, of qualitative and interpretative nature, and for that we have taken as a reference the researches of Ribeiro (2015) and Aquino (2018) that have submitted the usage of reading and writing to the social necessities of elementary school students. The results favor the idea of wor-king with argumentation as a privileged means to the end of forming individuals with political positions that demonstrate logical, plausible and ethical thinking inside and outside of school.

Keywords: Literacy. Argumentation. Portuguese language teaching.

\section{Introdução}

A vertente etnográfica dos estudos de letramento assume que as ações sociais dos cidadãos que vivem em sociedade grafocêntrica são mediadas por um conjunto de atividades que envolvem a língua escrita, em circunstâncias específicas e sempre direcionadas ao alcance de objetivos previamente estabelecidos (KLEIMAN, 1995). Isso implica compreender que é da situação social que emerge o "enquadramento" das ações que os agentes que dela participam podem desenvolver.

Nesse sentido, quando assistimos a aulas presenciais ou virtuaise fazemos anotações no caderno ou no tablet, enviamose-mails, preenchemos um formulário impresso ou digital, escrevemos um comentário a partir de uma publicação nas redes sociais, inserimos um recadinho na redação de um aluno, participamos de uma assembleia, debatemos sugestões de ação social na escola ou as enviamos a candidatos a cargo eletivo em período eleitoral, entre muitas outras ações cotidianas, estamos inseridos em situações concretas que requerem o desenvolvimento de 
V. $9(1)$

18-35

jan-abr

2019 práticas de letramento. Para tanto, não basta dominar o código alfabético nem as regras gramaticais da língua portuguesa, é preciso saber como articular habilidades, competências, saberes conceituais, atitudinais e procedimentais, além de diferentes tecnologias, em função de cada uma das necessidades interacionais de que participamos.

Em muitas dessas situações, há a necessidade de enfrentar embates de opinião e, nelas, nem sempre "vence" o sujeito mais justo ou o que preza pela legalidade de suas ações. A incipiente democracia brasileira vem demonstrando que, às vezes, o mais hábil pode levar vantagens, mesmo que sejam apenas pessoais e em detrimento de bem estar social. É nesse sentido que entendemos ser a argumentação uma competência fundamental para o desenvolvimento da formação cidadã.

De fato, desde o filósofo grego Aristóteles (séc. V a.C.), a argumentação, por meio da Retórica, é vista como um modo de empoderamento social. Com efeito, em pleno século XXI, as demandas sociais que requerem a defesa de um posicionamento, especialmente diante de situações polêmicas, aumentam a cada dia, e isso traz aos estudiosos da argumentação um importante desafio: a construção de propostas de ensino de argumentação que considerem as exigências sócio-históricas de nosso tempo.

Devido a isso, e considerando que o estudante é um ser social e histórico, "[...] pensante, comunicante, transformador, criador [...]" (FREIRE, 2003 [1996], p. 41), torna-se ainda mais relevante no Brasil identificar propostas sistematizadas de trabalho com o ensino de argumentação ancoradas na prática social vivencial e não simulada, pois cada um terá a oportunidade de assumir-se como sujeito com identidade cultural.

Para o desenvolvimento de uma proposta nessa perspectiva, defendemos a aplicação do modelo didático advindo dos projetos de letramento (KLEIMAN, 2000; TINOCO, 2008), os quais tomam como ponto de partida (e de chegada) práticas sociais mediadas pela escrita de circulação real, com interlocutores definidos e propósitos comunicativos compartilhados coletivamente em função de um objetivo comum.

Temos, então, o interesse de articular os estudos de letramento de vertente etnográfica ao ensino da argumentação para pensar em processos de ressignificação do ensino de língua portuguesa que vem sendo realizados por diferentes projetos de intervenção desenvolvidos, sobretudo, por professores vinculados ao Mestrado Profissional em Letras (Profletras), programa do qual participamos como formadoras e orientadoras. 
Desse grande esforço em rede nacional, ressaltaremos, na brevidade deste artigo, como o ensino da argumentação se integrou ao projeto de letramento desenvolvido por Aquino (2018)1, no Rio Grande do Norte, e orientou as práticas sistematizadas por Ribeiro (2015), na Bahia, quando ambas resolveram promover ações didáticas com base na participação discente em debates regrados. Em função de um recorte de dados desses dois trabalhos, desenvolvemos uma pesquisa exploratória, de natureza qualitativa e interpretativista, cuja análise tem como base as categorias teóricas e os dados já trabalhados por pesquisadores e devidamente registrados (MARCONI; LAKATOS, 2010).

Para organizar essa reflexão, este artigo está dividido em seis partes: nesta primeira, fazemos uma apresentação geral da proposta de trabalho; na segunda, apresentamos as principais bases teóricas que nos possibilitam discutir as possíveis articulações entre letramento e argumentação; na terceira, explicitamos os princípios que decorrem da correlação dos estudos de letramento e de argumentação com vistas à sistematização do ensino de argumentação como prática social; na quarta, analisamos duas experiências pedagógicas diferentes que se voltaram ao ensino da argumentação por meio de debates; na quinta, tecemos as considerações finais; por fim, explicitamos as referências mencionadas neste artigo.

\section{Relações entre o ensino de língua portuguesa e a argumentação}

Há aproximadamente vinte anos, os documentos oficiais brasileiros (BRASIL, 1997, 1998, 2000, 2002), que orientam o ensino de língua portuguesa na educação básica, apregoam a necessidade de os professores criarem condições para os estudantes participarem de práticas de linguagem que favoreçam o desenvolvimento da argumentação. A Base Nacional Comum Curricular (BNCC), cuja versão final foi publicada em dezembro de 2017, também explicita, entre os objetivos de aprendizagem de língua portuguesa, a importância de "[...] argumentar com base em fatos, dados e informações confiáveis, para formular, negociar e defender ideias, pontos de vista e decisões comuns que respeitem e promovam os direitos humanos e a consciência socioambiental [...]" (BRASIL, 2017, p. 18).

1 Embora os dados de Aquino (2018) sejam da pesquisa de doutorado (em desenvolvimento) no Programa de Pós-Graduação em Estudos da Linguagem (PPgEL), a referida doutoranda é egressa do ProfLetras. 
V. $9(1)$

18-35

jan-abr

2019

Em linhas gerais, a BNCC segue as proposições encontradas nos Parâmetros Curriculares Nacionais (PCN), publicados a partir de 1997, mas insiste nos mesmos problemas: (i) imprecisão conceitual, por exemplo, não há distinção entre as noções de argumentação e argumentatividade; (ii) falta de detalhamento dos conceitos que sustentam as orientações registradas no documento; (iii) ausência de indicações práticas que possam colaborar com o alcance dos objetivos, uma vez que os professores brasileiros carecem de formação específica relativa ao ensino da argumentação tanto na formação básica quanto continuada.

Em relação a esses aspectos, temos de enfatizar alguns pontos essenciais. Em primeiro lugar, argumentar e ensinar argumentação são ações distintas. Ao argumentar, o agente exerce a função crítica da linguagem tanto em situações cotidianas quanto em situações institucionalizadas. Ensinar argumentação, porém, pode se configurar como um exercício analítico que envolve a compreensão dos elementos centrais do texto argumentativo (tema, recorte temático, tese, argumentos, contra-argumentos, conclusão); uma atividade de leitura para identificar e classificar estratégias argumentativas encontradas em um texto; uma atividade de escrita de um gênero preponderantemente argumentativo sobre um tema polêmico selecionado pelo professor (ou sugerido pelo livro didático), que terá a finalidade de comprovar se o estudante sabe (ou não) engendrar argumentos em favor de uma tese. Essas práticas, entretanto, por si, não possibilitam aos sujeitos a construção da competência de argumentar socialmente. Isso se justifica porque tal competência requer o desenvolvimento de um conjunto de habilidades e de saberes articulados a interações sociais específicas.

Vinculado a essa perspectiva, o trabalho didático-pedagógico direcionado ao ensino da argumentação que encontra respaldo nos estudos de letramento de vertente etnográfica tem algo particular: ele se configura como uma oportunidade para estudantes, professores e até agentes externos à comunidade escolar, juntos, desenvolverem uma ação social significativa, de necessidade real e que estimula a liberdade de pensamento e de expressão.

Para essa ressignificação do trabalho didático-pedagógico, o conceito de projeto de letramento parece produtivo. De acordo com Kleiman (2000, p. 238), um projeto de letramento representa: 
Prática social em que a escrita é utilizada para atingir algum outro fim, que vai além da mera aprendizagem da escrita (a aprendizagem dos aspectos formais apenas), transformando objetivos circulares como 'escrever para aprender a escrever' e 'ler para aprender a ler' em ler e escrever para compreender e aprender aquilo que for relevante para o desenvolvimento e realização do projeto.

Essa perspectiva de trabalho envolve os usos da escrita na, para a e além da escola. Consequentemente, alarga o raio de ação de docentes e discentes movendo-os para lidar com outros usos sociais da escrita que ultrapassam a aprendizagem das convenções formais apenas. Ao associarmos essa perspectiva ao ensino da argumentação, podemos colaborar com o desenvolvimento de produções discursivas em que esses sujeitos precisem se posicionar diante de temas controversos, em situações de linguagem não simuladas pela escola, mas de embate real, entrelaçadas pelas estruturas político-econômicas e suas relações de poder. Essa "vivência" da argumentação pode ser um importante diferencial na constituição de agentes sociais que conseguem defender, com raciocínio lógico, plausível e ético (PERELMAN e OLBRECHTSTYTECA, 1996 [1958]) e ainda construir posicionamentos dentro e fora da escola (STREET, 2014 [1995]).

Com isso, queremos dizer que o ensino da argumentação, por meio de projetos de letramento, decorre de uma situação da vida cotidiana relevante para os sujeitos, marcada pelos elementos constitutivos da esfera social: aspectos econômicos, políticos, legais, relações de poder e espaços de contestação que podem estar fora da esfera escolar. Em síntese, essa proposta de ensino de argumentação implica a tomada de posição frente a outro(s) interlocutor(es), ou seja, uma análise cognitiva e discursiva, após o exame crítico da(s) problemática(s) cotidianas em discussão, eventualmente em disputa (PLANTIN, 2010 [1996]).

Em segundo lugar, ressaltamos que essa proposta toma como base a concepção de que é na interação em torno de um tema controverso que se constrói uma influência recíproca entre os interlocutores, o que permite a construção do discurso à medida que está sendo realizado pelos sujeitos envolvidos (PERELMAN, 1999). Assim, percebemos que, enquanto o diálogo acontece, ocorre a articulação de uma lógica discursiva, marcada por regras de organização e também por emoções, uma vez que as convicções de ambos, os valores sociais, os sentidos construídos na/ pela linguagem estão sendo questionados, reavaliados, reintroduzidos na discussão, transformados em outras visões no jogo da linguagem. 
V. 9 (1)

18-35

jan-abr

2019

Um terceiro ponto salientado aqui éo papel do professor no ensino da argumentação. Segundo Reboul (2004), o professor é um agente fundamental na capacitação do estudante que aprende a argumentar, visto que poderá colaborar de diferentes maneiras - ao prender a atenção dos estudantes em relação a um tema, ao ilustrar os conceitos de forma significativa para que possam assimilá-los melhor, ao estimular a reflexão pessoal, ao motivá-los durante a construção de conhecimentos - para o envolvimento de cada um em uma situação argumentativa, além de incentivar o discente a comparar as realidades antes de assumir posições sociais.

Nessa perspectiva, as ações de ensino que costumam se organizar a partir de uma relação assimétrica entre docentes e discentes precisam ser reconfiguradas em favor de uma perspectiva horizontal de aprendizagem na qual professores, estudantes e outros agentes internos e externos à escola possam construir juntos alternativas para haver novas aprendizagens em um contexto diferenciado e mais democrático com perspectivas variadas, pois

[...] O respeito à autonomia e à dignidade de cada um é um imperativo ético e não um favor que podemos ou não conceder uns aos outros. [...] O professor que desrespeita a curiosidade do educando, o seu gosto estético, a sua inquietude, a sua linguagem, mais precisamente, a sua sintaxe e a sua prosódia; [...] que se furta ao dever de ensinar, de estar respeitosamente presente à experiência formadora do educando, transgride os princípios fundamentalmente éticos de nossa existência. [...] (FREIRE, 2003 [1996], p. 59-60).

De fato, se tomamos a argumentação como uma prática discursiva, observamos que as condições para que nossa participação social se efetive de forma mais autônoma exige um movimento de interpretação da realidade (perspectiva cognitiva e linguística), de análise de argumentos favoráveis e contrários a uma posição social (perspectiva lógica e crítica) e de assunção de um posicionamento justificado (perspectiva cultural e política).

Essa compreensão parece-nos indicar que, em alinhamento às ideias de Plantin (2010 [1996], p. 19-20), a argumentação é uma "[...] atividade linguística acompanhada de uma atividade de pensamento", que tem como resultado concreto enunciações construídas em situação de interação, ou seja, em situações dialógicas e discursivas, cujos meios para alcançar a persuasão do outro estão apoiados na diferença de posições (dissensos ou consensos parciais) e podem ser avaliados em função dos critérios estabelecidos pelos interlocutores. 
Com base nessas concepções, propomos alguns princípios de como o ensino de argumentação pode se operacionalizar em práticas pedagógicas, o que será exposto com base nas ações didáticas organizadas por Ribeiro (2015), entendida neste artigo como a experiência 1, e em um projeto de letramento desenvolvido por Aquino (2018), a experiência 2.

\section{Princípios do ensino de argumentação como prática social}

Associar o ensino de argumentação às práticas sociais de linguagem, próprias da vida em sociedade, requer, em primeiro lugar, que o professor conheça os estudantes e, principalmente, os interesses deles. No caso de Ribeiro (2015), o trabalho pedagógico foi realizado em uma escola pública do interior da Bahia, com trinta e oito estudantes, com idades entre treze e quinze anos, matriculados no $9^{\circ}$ ano do ensino fundamental, dos quais vinte e seis deles residiam na zona rural, alguns eram egressos de turmas multisseriadas, e a maioria demonstrava interesse em participar das atividades escolares, apesar das dificuldades pontuais em escrita, oralidade, leitura e produção textual identificadas pela professora. Aquino (2016), por sua vez, desenvolveu um projeto de letramento também com uma turma do $9^{\circ}$ ano, de uma escola pública do interior do Rio Grande do Norte, composta por estudantes com faixa etária compreendida entre treze e vinte anos, sendo dezoito do sexo feminino e dois do sexo masculino, que tinham um interesse em comum: discutir o problema da falta de água potável no município de Portalegre.

O segundo princípio decorre do trabalho com textos de circulação social externa à escola. Na experiência 1, os livros literários clássicos e atuais, desconhecidos por falta de acesso dos estudantes a uma biblioteca, passaram a integrar as práticas realizadas em sala de aula por meio de uma biblioteca de classe, em torno de cinco questões retóricas ${ }^{2}$ (1. A violência doméstica é uma maneira de educar? 2. Relação pais e filhos: o que vale é a autoridade ou o autoritarismo? 3. A fé em Deus e os princípios religiosos podem tornar uma pessoa melhor? 4. Relação professor, escola e aluno: essa relação é sempre harmoniosa? 5. Relação entre os idosos e os jovens: realmente existe o respeito?), decorrentes da leitura da novela Meu pé de laranja lima, do escritor José Mauro de Vasconcelos. Essas questões foram

\footnotetext{
${ }^{2}$ Entende-se por questão retórica "[...] o objeto da discussão, o motivo que gera dúvida, incompatibilidade. É, enfim, um problema que precisa ser resolvido, pois se sabe que a solução implica mais de uma resposta. [...] O problema retórico sempre é uma construção simbólica da realidade, pois envolve um contexto de realidade que se soma à interpretação de quem a vivencia (FERREIRA, 2010, p. 54-55, grifos do autor).
} 
V. $9(1)$

$18-35$

jan-abr

2019

elaboradas coletivamente entre os estudantes com a mediação da professora. Além disso, diferentes materiais impressos e disponíveis na internet foram consultados (depoimentos orais e escritos, artigos de opinião, reportagens e vídeos encontrados no YouTube, por exemplo) e integraram-se às atividades diárias a fim de possibilitar aos estudantes selecionar as informações que poderiam colaborar com a formulação de argumentos e contra-argumentos.

Na experiência 2, ao buscar respostas para um problema específico - quais seriam as medidas possíveis para o enfrentamento da crise hídrica vivenciada em Portalegre? ${ }^{3}$-, em um fazer colaborativo, o grupo precisou lidar com textos corporificados em diferentes gêneros: um artigo de opinião divulgado no site Carta Potiguar e as audições de profissionais convidados para participação em entrevistas e mesas-redondas (uma professora da UFRN especialista em gestão ambiental e recursos hídricos, vereadores e alguns candidatos a vereador do município concorrentes ao pleito de 2016, o prefeito municipal, a secretária de educação de Portalegre/RN, o diretor local da CAERN e o representante municipal da defesa civil, bem como alunos de outras instituições de ensino).

O terceiro princípio diz respeito ao professor, visto que, como especialista da linguagem, cumpre a função de sistematizar o ensino de leitura crítica dos textos multissemióticos, de enunciar os procedimentos que favoreçam a prática material do letramento, com o intuito de auxiliar o estudante a lidar com os textos e com as convenções orais e escritas nem sempre explicitamente enunciadas, e de colaborar com a organização das relações sociais presentes em classe. Por conseguinte, fica explicitada a necessidade de participação direta, por meio de respostas orais e escritas, em situações que se mostrem relevantes para a continuidade das práticas de linguagem e do projeto como um todo. Isso ocorre porque os aspectos técnicos da leitura e da escrita estão associados às práticas sociais particulares, entendidas como processos de socialização da leitura e da escrita construídos historicamente e pelas relações de poder entre grupos engajados em práticas letradas diferentes que são cruciais para o entendimento de questões e problemas específicos (STREET, 2014 [1995]). Assim, caso haja gêneros com os quais o docente tenha pouca (ou nenhuma) familiaridade, solicitar o auxílio de agentes externos à sala de aula também se configura como um princípio dos projetos de letramento e, em geral, isso tem sido realizado com uma aceitação muito favorável.

\footnotetext{
3 Essa temática foi escolhida entre várias outras opções associadas a seis campos temáticos: (i) educação e atrativos para os jovens; (ii) infraestrutura e manutenção de órgãos públicos; (iii) saúde pública; (iv) segurança pública; (v) problema social/ particular; (vi) política.
} 
Ribeiro (2015) e Aquino (2018), ao refletirem em defesa dos letramentos sociais, realizaram um ato solidário e comprometido com homens e mulheres, agindo em favor da humanização (FREIRE, 2016). Nesse sentido, os modos como professores, estudantes e outros agentes sociais interagem já é uma prática social que afeta a natureza do letramento e as ideias sobre letramento sustentadas pelos participantes, além de indicar o compromisso profissional com a sociedade.

Em função da natureza desse tipo de trabalho, destacamos um quarto princípio: a expansão do continuum entre leitura, escrita e oralidade (AQUINO, 2018). Nas práticas de letramento, há situações em que é a oralidade menos ou mais formal - a depender do evento de que estiverem participando - que vai operacionalizar respostas (ou trazer novas perguntas) a essa ação coletiva. Em outras situações, as práticas de ler, escrever, ouvir e falar ${ }^{4}$ estão imbrincadas em função de um mesmo propósito comunicativo. Logo, a didatização das práticas de linguagem de diferentes modalidades e semioses dependerá das ações desenvolvidas no curso das atividades realizadas coletivamente. Em ambas as experiências, as atividades realizadas antes e durante os debates, reforçam como a expansão do continuum colabora com o desenvolvimento do letramento social, conforme indicamos no quadro 1.

Quadro 1 - Atividades voltadas ao desenvolvimento do letramento

\begin{tabular}{|c|c|}
\hline ANTES DO DEBATE & DURANTE O DEBATE \\
\hline $\begin{array}{l}\text { Leitura de exemplares de variados } \\
\text { gêneros discursivos, seguida de } \\
\text { comentários dos leitores. }\end{array}$ & $\begin{array}{l}\text { Oralização de perguntas e/ou proposições } \\
\text { destinadas aos debatedores. }\end{array}$ \\
\hline $\begin{array}{l}\text { Preparação do debate, incluindo escritas } \\
\text { variadas (perguntas para entrevistas, } \\
\text { elaboração de argumentos). }\end{array}$ & $\begin{array}{l}\text { Explicitação oral de argumentos e de } \\
\text { contra-argumentos em função dos } \\
\text { elementos mencionados no momento da } \\
\text { interacão. }\end{array}$ \\
\hline $\begin{array}{l}\text { Produções orais e escritas diversificadas, } \\
\text { como a primeira versão do debate } \\
\text { (filmada em classe), charge sobre a } \\
\text { problemática em estudo. }\end{array}$ & $\begin{array}{l}\text { Análise dos argumentos e das refutações } \\
\text { apresentados e avaliação da participação } \\
\text { dos diferentes sujeitos vinculados aos } \\
\text { debates. }\end{array}$ \\
\hline
\end{tabular}
Fonte: Elaborado a partir de Ribeiro (2015) e Aquino (2018).

O quadro 1 sinaliza que ambas as professoras elaboraram planejamentos detalhados, que incluíram análises discursivas ("leitura de exemplares de variados gêneros discursivos", "escritas variadas"; "produções orais") e intercâmbio de comunicação tanto na modalidade oral

\footnotetext{
${ }^{4}$ A relação de continuum entre leitura e escrita foi inicialmente proposta por Marcuschi (2001). Porém, nos dados de Aquino (2018), percebemos que esse continuum se expande entre ações de leitura, escrita e oralidade em função das condicionantes de cada situação comunicativa. Para saber melhor sobre essa expansão conceitual, sugerimos a leitura de Aquino (2018).
} 
V. $9(1)$

18-35

jan-abr

2019

quanto escrita ("oralização de perguntas", "explicitação oral de argumentos e contra-argumentos", "avaliação da participação dos diferentes sujeitos"), derivadas da interação entre os participantes. A reflexão mobilizada para a análise das questões sociais também foi colocada a serviço da identificação das causas para os acontecimentos, da construção de argumentos e da formulação de alternativas para a resolução dos problemas. Após o debate, porém, as ações foram bem diferentes, razão por que esse ponto será aprofundado na próxima parte deste artigo.

A afirmação desses quatro princípios nos faz ressaltar que, nos projetos de letramento, a argumentação não se coloca simplesmente como um objeto de ensino nem pode ser reduzida à argumentatividade, uma vez que se desenvolve em uma (ou várias) situação(ões) comunicativa(s) específica(s), quando os sujeitos estão em interação, promovida pela oposição entre discursos, pela alternância de turnos e pela interdependência discursiva (GRÁCIO, 2010). Em função disso, destacamos que o uso da argumentação se evidencia em eventos nos quais agentes internos e externos defendem posicionamentos acerca de uma problematização situada.

\section{Análise argumentativa das produções associadas aos eventos de letramento}

Ribeiro (2015) assumiu o debate regrado como um gênero discursivo oral e estabeleceu como objetivo desenvolver a argumentação dos estudantes e, ao mesmo tempo, o letramento literário. Embora tenha assumido como referência as orientações de Dolz, Schneuwly e Pietro (2004), implementou adaptações consideradas necessárias para que o estudo da argumentação oral acontecesse de modo sistematizado, estimulasse a localização de lugares discursivos que pudessem favorecer a constituição de argumentos direcionados à defesa de um ponto de vista e a discussão das questões retóricas a serem discutidas em grupos. Nesse sentido, o debate tornou-se o meio para o desenvolvimento de competências argumentativas, visto que, na sondagem, os estudantes demonstraram saber fundamentar suas opiniões apenas a partir de ilustrações, selecionar de maneira limitada as informações pertinentes à temática em discussão e pouca desenvoltura na sustentação e negociação das ideias.

Aquino (2018), por sua vez, compreende o debate regrado como um evento de letramento integrado a uma rede de atividades de leitura, de escrita e de oralidade, as quais compõem um projeto de 
letramento (mais amplo) do qual o debate é um dos eventos. Nessa articulação de gêneros orais, escritos e multimodais como instrumentos de viabilização para ações sociais específicas, os gêneros discursivos não são definidos a priori. Eles emergem no decurso das ações, cumprindo funções comunicativas e sociais. Nesse processo, a professora pretendeu ressignificar o ensino da argumentação, uma vez que os estudantes puderam argumentar ao realizar ações específicas: escrita (e reescrita) de carta de solicitação; leitura de dados informacionais sobre o problema a ser debatido; produção de perguntas que seriam apresentadas oralmente a vereadores durante o debate; elaboração de perguntas espontâneas no decorrer do debate. O conjunto dessas ações colaborou para o desenvolvimento de diferentes competências argumentativas.

Entre o trabalho de Ribeiro (2015) e o de Aquino (2018), observamos algumas diferenças significativas, sintetizadas no quadro 2.

Quadro 2 - Duas possibilidades de entendimento do debate regrado

\begin{tabular}{|c|c|}
\hline GÊNERO DISCURSIVO & EVENTO DE LETRAMENTO \\
\hline $\begin{array}{llr}\text { Parte de uma temática } & \text { (social) } \\
\text { controversa pré-estabelecida } & \text { ou } \\
\text { acordada em grupo. } & & \\
\end{array}$ & $\begin{array}{l}\text { Parte de uma problemática social situada } \\
\text { que interessa a um determinado grupo. }\end{array}$ \\
\hline $\begin{array}{l}\text { Decorre de objetivos variados e visa à } \\
\text { compreensão das características próprias } \\
\text { do gênero. }\end{array}$ & $\begin{array}{l}\text { Decorre de um projeto de letramento } \\
\text { enquanto modelo didático (TINOCO, } \\
\text { 2008). }\end{array}$ \\
\hline $\begin{array}{l}\text { Parte de uma situação comunicativa } \\
\text { concreta ou de um tópico escolar e visa } \\
\text { à discussão de uma questão problema } \\
\text { e à aprendizagem dos mecanismos do } \\
\text { debate. }\end{array}$ & $\begin{array}{l}\text { Representa uma situação comunicativa } \\
\text { concreta em que os participantes } \\
\text { procuram, coletivamente, uma solução } \\
\text { para o problema em foco. }\end{array}$ \\
\hline $\begin{array}{l}\text { E realizado em uma situação concreta } \\
\text { de fala e depende da interação entre as } \\
\text { pessoas. }\end{array}$ & $\begin{array}{l}\text { É um evento único em que a leitura, } \\
\text { a escrita e a oralidade desempenham } \\
\text { diferentes papéis. }\end{array}$ \\
\hline $\begin{array}{l}\text { Requerplanejamento, regraspreviamente } \\
\text { acordadas para a sua realização, como as } \\
\text { trocas de turnos entre os debatedores e } \\
\text { avaliacão. }\end{array}$ & $\begin{array}{l}\text { Aprende-se a argumentar, } \\
\text { argumentando, visto que as necessidades } \\
\text { comunicativas vão se apresentando ao } \\
\text { longo das acões. }\end{array}$ \\
\hline $\begin{array}{l}\text { Apoia-se em recursos próprios da } \\
\text { modalidade oral da língua e nas } \\
\text { estratégias argumentativas que podem } \\
\text { qualificar as ações argumentativas. }\end{array}$ & $\begin{array}{l}\text { Associa-se a uma rede de atividades/ } \\
\text { gêneros que estão vinculados às ações } \\
\text { de planejamento, de execução e de } \\
\text { consecução do debate. }\end{array}$ \\
\hline $\begin{array}{l}\text { Participantes: moderador, equipes de } \\
\text { defesa de pontos de vista diferentes, } \\
\text { que também realizam a contra- } \\
\text { argumentacão. }\end{array}$ & $\begin{array}{l}\text { Participantes: estudantes e professores } \\
\text { envolvidos no projeto, convidados } \\
\text { (internos e externos à escola). }\end{array}$ \\
\hline $\begin{array}{l}\text { Promove a defesa de pontos de vista } \\
\text { que visam persuadir o outro, e cada } \\
\text { participante pode também ter suas } \\
\text { ideias transformadas pela interação com } \\
\text { o outro. }\end{array}$ & $\begin{array}{l}\text { Depende dos elementos visíveis } \\
\text { (ambiente, participantes, artefatos e } \\
\text { atividades) e não visíveis (domínio das } \\
\text { práticas, valores não materiais, rotinas } \\
\text { estruturadas e traietos). }\end{array}$ \\
\hline
\end{tabular}


V. $9(1)$

18-35

jan-abr

2019

Como vemos no quadro 2, o desenvolvimento dos estudantes em cada uma das perspectivas de trabalho com o debate regrado em classe depende da participação diferenciada deles em atividades diversificadas, com características bem distintas. Na experiência 1, as ações didáticas colaboram com o acompanhamento e a avaliação das aprendizagens de cada discente pela professora, pois todos são desafiados a discutir diferentes temáticas em classe e em diferentes espaços sociais. Já na experiência 2, os estudantes puderam assumir papeis sociais específicos de acordo com uma meta estabelecida coletivamente, o que permitiu atuarem como agentes de transformação social. Em comum, notamos que ambas as experiências implicaram os estudantes na argumentação, entendida, neste artigo, como um processo discursivo, complexo e multidimensional que proporciona, pelo diálogo, a ampliação da autonomia intelectual que possibilita superar condições opressoras, impostas pelas circunstâncias sociais.

Embora distintas, as duas perspectivas de trabalho com o debate regrado, registradas por Ribeiro (2015) e Aquino (2018), possibilitaram observar que os estudantes puderam desenvolver ao menos cinco capacidades argumentativas 5 . Vejamos.

1 - Analisar informações e opiniões em diferentes situações de interação e a partir da leitura de exemplares de variados gêneros discursivos.

Na experiência 1, destaca-se a variedade de fontes consultadas para o aprofundamento das questões retóricas escolhidas para suscitar os debates; na experiência 2, a rede de atividades/gêneros discursivos gerou um movimento de colaboração e de interligação entre todas as ações que constituem os eventos de letramento.

2 - Identificar e fazer uso de argumentos e de estratégias argumentativas em gêneros discursivos situados (orais, escritos e multimodais), orientados por funcionalidades sociais específicas.

\footnotetext{
5 Tomamos a capacidade argumentativa como um conceito que está associado à produção de discursos, especialmente quando esses discursos se concretizam em gêneros preponderantemente argumentativos que requerem a mobilização de recursos historicamente organizados. Segundo Azevedo (2016), a capacidade argumentativa é uma condição humana que inter-relaciona a linguagem verbal e a reflexão em torno dos objetos do mundo (atividade cognitiva e social), um modo de expressão que se apoia em já-ditos e alinha-se às regras sociais, por isso está submetida às coerções de uso social da linguagem (atividade discursiva) e uma ação de linguagem gerada a partir de uma oposição discursiva que gera interdependência entre os sujeitos (atividade dialógica).
} 
Na experiência 1, os gêneros discursivos variaram conforme a temática reservada a cada grupo, mas o estudo relativo às possibilidades de composição de argumentos, contra-argumentos e resposta (cf LEITÃO, 2011) foi realizado coletivamente a partir da pesquisa em artigos de opinião, vídeos, sites informativos. Na experiência 2, as atividades/gêneros discursivos foram selecionados em função do evento de letramento, ou seja, os estudantes participaram de exposições orais, da escrita colaborativa de cartas de solicitação, da elaboração de perguntas, por exemplo, porque isso viabilizaria a consecução do debate entre a comunidade escolar e os vereadores acerca da crise hídrica do município de Portalegre.

3 - Refletir acerca dos argumentos com os quais se deparam nas práticas sociais de diferentes esferas de comunicação, de modo a concordar e/ou discordar deles.

Na experiência 1, essa capacidade permeou várias atividades e constituiu o centro das atenções da professora e dos estudantes, uma vez que estes últimos teriam de participar efetivamente de um debate que contaria com a presença de diferentes integrantes da comunidade escolar e de personalidades da secretaria da educação. Para tanto, analisaram debates alheios e os próprios a fim de demarcar os argumentos e os contra-argumentos, bem como as respostas constituídas a partir da interdependência entre os sujeitos. Como, a princípio, os estudantes não apresentaram muita habilidade em relação à exposição oral de pontos de vista numa situação dialógica (alguns externavam posicionamentos com truncamentos, não conseguiam formular e expor conclusivamente a ideia pretendida, alegavam não dominar a expressão oral adequadamente), a mediação do professor foi um elemento singular para que houvesse troca de experiências, ampliação de conhecimentos e assunção de atitudes concretas frente ao outro, durante a participação de todos em um debate em torno de uma questão retórica.

$\mathrm{Na}$ experiência 2, a partir do envolvimento em diferentes atividades/gêneros discursivos (leitura de artigo de opinião, escrita/ oralização de perguntas para serem respondidas no debate, enunciação de perguntas espontâneas no bloco destinado a esse fim, escrita de carta argumentativa), foi possível perceber que os estudantes articularam, coletivamente, várias estratégias argumentativas. Entre elas, duas foram majoritárias: (i) argumento de causa e efeito, para 
V. 9 (1)

18-35

jan-abr

2019

explicar as possíveis relações entre a falta de água, a qualidade de vida e o compromisso social de cada cidadão (seja eleitor seja representante político municipal) em relação a esse problema social; (ii) ilustração de situações, para refletir sobre a gravidade desse problema que aflige o município como um todo. No processo, o grupo identificou argumentos com os quais poderia concordar ou não, o que marca o processo interacional da argumentação enquanto prática social. Ao assumir diferentes tarefas, os estudantes tornaram-se efetivamente agentes de letramento (KLEIMAN, 2006; FERNANDES, 2015) e colaboraram, direta ou indiretamente, na constituição de um debate regrado com os convidados para discutir a crise hídrica de Portalegre, bem como possíveis intervenções posteriores.

4 -Ouvir as diferentes posições acerca de uma problemática, desenvolvendo uma consciência crítica.

Na experiência 1, uma etapa importante do planejamento das ações incluiu o autoexame, ou seja, um debate produzido pelos estudantes foi gravado e analisado por todos. Esse procedimento estimulou a ação de aprender a aprender, reconstruir ideias e (re)ações, ampliar as problematizações, aprimorar a escolha de recursos e a tomada de decisão que possibilita a construção de posicionamentos discursivos, além de permitir o cultivo da humildade. Na experiência 2, a oportunidade de ouvir diferentes interlocutores (internos e externos à escola) permitiu observar não apenas o conteúdo e a forma do dizer, mas também as posições dos interlocutores que estavam em um embate concreto de opiniões em função de uma problemática em comum durante o debate organizado pelos estudantes.

5 - Participar efetivamente de situações em quea argumentação se faz necessária.

Na experiência 1, a participação dos estudantes esteve restrita às circunstâncias pertinentes à discussão das questões retóricas que, embora tivessem sido formuladas por eles, interessavam especificamente uma turma da escola. Na experiência 2, houve efetivo exercício da cidadania dos estudantes como agentes sociais que refletem sobre uma situação-problema vivencial e tomam atitudes perante aquilo que os incomoda. 


\section{Considerações Finais}

A reflexão que desenvolvemos neste artigo nos permite afirmar que os estudos de letramento se coadunam bem como uma proposta de ensino da argumentação como competência essencial para a formação cidadã. Nessa proposta, os dois trabalhos pedagógicos (um conjunto de ações voltadas ao desenvolvimento da argumentação e do letramento literário e um projeto de letramento no qual um dos eventos é o debate regrado) evidenciaram a existência de princípios recorrentes: (i) a situacionalidade do ensino de argumentação; (ii) o trabalho com textos multissemióticos de circulação externa ao ambiente escolar; (iii) a participação de agentes externos à escola para que, junto com professores e estudantes, defendam seus posicionamentos e, assim, evidenciem uma maior multiplicidade de olhares sobre o problema elencado; (iv) ampliação do continuum entre leitura, escrita e oralidade.

Diante do exposto, a proposta de ensino da argumentação como prática social ressignifica o processo porque, ao focalizar o uso da argumentação, torna-o vivencial. Com isso, o trabalho com a argumentação passa a ser um meio privilegiado para formar sujeitos com posicionamentos políticos que demonstrem raciocínio lógico, plausível e ético dentro e fora da escola.

\section{Referências}

AQUINO, Jaciara Limeira de. Ressignificação do ensino de argumentação em eventos de letramento. 2018. Tese (Doutorado no Programa de Pós-graduação em Estudos da Linguagem). Universidade Federal do Rio Grande do Norte, Natal, 2018.

AZEVEDO, Isabel. C. M. Capacidades argumentativas de professores e estudantes da educação básica em discussão. In: Piris, E. L.; Olímpio-Ferreira, M. (org.). Discurso e Argumentação em múltiplos enfoques. Coimbra: Grácio Editor, 2016. p. 167-190.

BRASIL. Base Nacional Comum Curricular (versão final). 2017. Disponível em: <http://basenacionalcomum.mec.gov.br/>. Acesso em: 10 jun. 18.

BRASIL. Ministério da Educação. Secretaria de Educação Fundamental. Parâmetros Curriculares Nacionais: língua portuguesa. Brasília: MEC, 1997.

Ministério da Educação. Secretaria de Educação Fundamental. Parâmetros curriculares nacionais: terceiro e quarto ciclos do ensino fundamental: língua portuguesa Brasília: MEC/SEF, 1998. 
v. 9 (1)

18-35

jan-abr

2019
Ministério da Educação. Secretaria de Educação Média e Tecnológica. Parâmetros Curriculares Nacionais (Ensino Médio). Brasília: MEC, 2000.

Ministério da Educação. Secretaria da Educação Média e Tecnológica. PCN+: Ensino Médio - Orientações Educacionais Complementares aos Parâmetros Curriculares Nacionais. Linguagens, códigos e suas tecnologias. Brasília: MEC, 2002.

DOLZ, Joaquim, SCHNEUWLY, Bernard; PIETRO, Jean-François de. Relato da elaboração de uma a sequência: o debate público. In: SCHNEUWLY, Bernard; DOLZ, Joaquim. Gêneros orais e escritos na escola. Tradução e organização de Roxane Rojo e Glaís Sales Cordeiro. Campinas, SP: Mercado de Letras, 2004. p. 247-278.

FERNANDES, Francisca Vaneíse Andrade. Olimpíada de Língua Portuguesa: ressignificação de práticas de leitura e escrita. 2015, 138f. Dissertação (Mestrado Profissional em Letras) - Universidade Federal do Rio Grande do Norte, Natal, 2015.

FERREIRA, Luiz Antonio. Leitura e persuasão - princípios de análise retórica. São Paulo: Contexto, 2010.

FREIRE, Paulo. Pedagogia da autonomia: saberes necessários à prática educativa. 28. ed. São Paulo: Paz e Terra, 2003 [1996].

Educação e mudança. Trad. Lilian Lopes Martin. 37. ed. rev. e atual. São Paulo: Paz e Terra, 2016.

GRÁCIO, Rui Alexandre. A interacção argumentativa. Coimbra: Grácio Editor, 2010.

HAMILTON, Mary. Expanding the New Literacies Studies: using photographs to explore literacy as social practices. In: BARTON, David; HAMILTON, Mary; IVANIC, Roz (org.). Situated Literacies: Reading and writing in context. London: Routledge, 2000. p. 16-34.

KLEIMAN, Angela B. (org.). Os significados do letramento: uma nova perspectiva sobre a prática social da escrita. Campinas, SP: Mercado de Letras, 1995.

O processo de aculturação pela escrita: ensino de forma ou aprendizagem da função? In: KLEIMAN, Angela. B.; SIGNORINI, Inês. O ensino e a formação do professor: alfabetização de jovens e adultos. Porto Alegre: Artmed, 2000. p. 223-243.

Processos identitários na formação profissional: o professor como agente de letramento. In: CORRÊA, Manoel Luiz Gonçalves; BOCH, Françoise (org.). Ensino de língua: representação e letramento. Campinas, SP: Mercado de Letras, 2006. p. 75-91.

LEITÃO, Selma. O lugar da argumentação na construção do conhecimento em sala de aula. In: LEITÃO, Selma; DAMIANOVIC, Maria Cristina (org.). Argumentação na escola: o conhecimento em construção. Campinas, SP: Pontes Editores, 2011. p. 13-46. 
MARCONI, Marina de Andrade; LAKATOS, Eva Maria. Fundamentos da metodologia científica. 7. ed. SP: Atlas, 2010.

MARCUSCHI, Luiz Antonio. Da fala para a escrita: atividades de retextualização. 2. ed. São Paulo: Cortez, 2001.

PERELMAN, Chaïm; OLBRECHTS-TYTECA, Lucie. Tratado da argumentação: a nova retórica. Tradução de Maria Ermantina Galvão. São Paulo: Martins Fontes, 1996.

PERELMAN, Chaïm. o império retórico. Retórica e Argumentação. 2. ed. Tradução de Fernando Trindade e Rui Alexandre Grácio. Porto: ASA Editores, 1999.

PLANTIN, Christian. A argumentação. Tradução de Rui Alexandre Grácio e Martina Matozzi. Coimbra: Grácio Editor, 2010 [1996].

REBOUL, Olivier. Introdução à retórica. Tradução de Ivone Castilho Benedetti. São Paulo: Martins Fontes, 2004.

RIBEIRO, Nadja Souza. Literatura em debate: possibilidades para o desenvolvimento da capacidade argumentativa oral no $9^{\circ}$ ano. 2015. 106 f. Dissertação (Mestrado Profissional em Letras) - Universidade Federal de Sergipe, São Cristóvão, 2015.

STREET, Brain V. Letramentos sociais. Abordagens críticas do letramento no desenvolvimento, na etnografia e na educação. Tradução de Marcos Bagno. São Paulo: Parábola, 2014 [1995].

TINOCO, Glicia Azevedo. Projetos de letramento: ação e formação de professores de língua materna. 2008, 254f. Tese (Doutorado em Linguística Aplicada) Instituto de Estudos da Linguagem, Universidade Estadual de Campinas, São Paulo, 2008.

TINOCO, Glicia Azevedo; AQUINO, Jaciara Limeira de. Debate regrado como evento de letramento. In: Gelne 40 anos. São Paulo: Pá de Palavra. 2018. p. 161-180. V. 2 